\title{
Selective Arterial Embolization in Intractable Recurrent Epistaxis: A Clinical Analysis with Literature Review
}

\author{
Myoung Su Choi, Seung-Gu Park, No Seon Park, Ji Chan Kim, \\ Ho Yun Lee, Dong Sik Chang, Chin Saeng Cho, and Ah-Young Kim \\ Department of Otolaryngology-Head and Neck Surgery, College of Medicine, Eulji University, Daejeon, Korea
}

\author{
선택적 동맥 색전술을 이용한 난치성 재발성 비출혈 환자의 치료: 임상양상 분석 및 문헌고찰 \\ 최명수 · 박승구 · 박노선 · 김지찬 · 이호윤 · 장동식 · 조진생 · 김아영 \\ 을지대학교 의과대학 이비인후과학교실
}

\author{
Received July 29, 2014 \\ Revised September 25, 2014 \\ Accepted October 13, 2014 \\ Address for correspondence \\ Ah-Young Kim, MD \\ Department of Otolaryngology- \\ Head and Neck Surgery, \\ College of Medicine, \\ Eulji University, \\ 95 Dunsanseo-ro, Seo-gu, \\ Daejeon 302-799, Korea \\ Tel $+82-42-611-3129$ \\ Fax $+82-42-611-3136$ \\ E-mail kimayong@eulji.ac.kr
}

\begin{abstract}
Background and Objectives Epistaxis usually responds to conservative therapy such as nasal packing or electrocauterization. But sometimes more invasive techniques such as selective embolization is justified. We report our experience of 10 patients with selective endovascular embolization for refractory epistaxis.

Subjects and Method Ten patients were referred for selective arterial embolization for refractory epistaxis. Medical records were reviewed for clinical data, recurrence, and complication. Results Early rebleeding requiring treatment occurred in 1 patient (10\%) and initial success rate of embolization was $90 \%$. There was no major complication. Minor complications such as mild fever, groin pain, and voiding difficulty occurred in 2 patients $(20 \%)$.

Conclusion Selective arterial embolization for refractory epistaxis is safe and effective for treatment of refractory intractable epistaxis.

Korean J Otorhinolaryngol-Head Neck Surg 2015;58(4):257-60

Key Words Embolization · Epistaxis · Nose.
\end{abstract}

\section{서 론}

비출혈은 전체 인구의 약 $60 \%$ 에서 경험하며, 이 중 약 $6 \%$ 정 도는 입원치료를 요하는 것으로 보고되고 있다. ${ }^{1)}$ 대부분의 비출혈은 전, 후비공 패킹, 화학적 또는 전기적 소작술, 레이 저 소작술 등의 보존적인 치료로 치료가 가능하다. 그러나 이와 같은 보존적 방법으로 해결되지 않는 난치성 비출혈의 경우 선택적 동맥 색전술(selective arterial embolization)이 효과적인 방법 중의 하나로 이용되고 있다.

국내에서는 Park 등리 이 내시경하 부비동 수술 후 발생한 경우 및 혈관 섬유종을 포함한 19예의 비출혈 환자를 대상 으로 동맥 색전술이 효과적인 치료방법임을 보고한 바 있으 나, 그 이외에는 보고가 드물어 국내에서의 동맥 색전술의 유용성이나 실제 치료 성공률 등에 대해서는 더 많은 연구보
고가 필요할 것으로 생각된다. 이에 저자들은, 원인미상의 난 치성 비출혈 환자 10예를 선택적 동맥 색전술을 이용하여 치 료한 바 있어 이를 보고하고자 한다.

\section{대상 및 방법}

2009년 1월 1일부터 2013년 12월 30일까지 5년간 원인미 상의 비출혈로 본원 이비인후과를 내원한 환자 중 선택적 동 맥 색전술을 시행 받은 10명의 환자(남자 6명, 여자 4명, 평균 연령 46.6세)를 대상으로 후향적으로 임상 기록을 조사하였 으며, 이 연구는 본원 임상시험심사위원회(Institutional Review Board)의 승인을 받았다. 우선적으로 출혈부위가 추정되는 경우는 전기 소작술을 이용하여 치료가 이루어졌으며, 내원 당 시 출혈부위가 관찰되지 않는 재발성 비출혈 환자나 대량 출혈 
로 출혈 부위를 관찰할 수 없는 경우 바셀린 거즈 및 Merocel (Medtronic Xomed, Jacksonville, FL, USA)을 이용하여 비강 패킹을 시도하였다. 여러 차례의 비강 패킹에도 치료되지 않고 반복되는 경우, 비강 내 출혈부위라고 추정되는 비강 후방 지 점을 전기 소작술을 시행하였음에도 불구하고 다시 후방 비 출혈이 발생하였던 경우, 출혈부위를 알 수 없을 정도로 급작 스런 대량 출혈이 있으며 비강 패킹으로도 멈추지 않는 경우 등 보전적 치료에도 효과가 없는 경우를 대상으로 선택적 동맥 색전술을 시행하였다. 다만, 내, 외경동맥 사이의 비정상적인 문합이 있는 경우, 조영제 과민증, 심각한 동맥 경화증 등의 경 우는 동맥 색전술을 시행하지 않았다.

선택적 동맥 색전술은 전문 중재적 방사선과 전문의에 의 해서 시행되었으며, 국소 마취하에 우측 대퇴동맥을 경유하여 6 8 French 크기의 도관 및 $0.010 \mathrm{inch}$ 미세도관을 사용하여 양측 외경동맥 및 내경 동맥의 혈관 조영술을 우선적으로 시 행하여 출혈부위 및 혈관 이상을 확인하고자 하였으며, 조영 제의 비강 내 혈관외 유출이 나타나 출혈부위가 확인된 경우 에는 출혈부위에 최대한 접근하여 색전술을 시행하였다(Fig. 1). 출혈부위의 확인이 불가능하였던 경우에는 동측 내상악 동맥 (internal maxillary artery, IMA)의 세 번째 부분(3rd portion, pterygomaxillary portion)에 선택적 색전술을 시행하였다. 색전술에 이용된 물질로는 대부분 150 250 $\mu \mathrm{m}$ 크기의 polyvinyl alcohol(PVC)(Contou, Boston scientific, Boston, MA, USA)을 사용하였다. 2예의 경우 출혈량 및 빈혈이 심하여 glue 를 이용한 1 예의 경우는 완전히 혈관을 폐색하기 위하여 $25 \%$ glue(Histoacryl, B/Braun, Aesculap AG Et Co, Germany)를 이 용, 다른 1예는 PVC 및 $20 \%$ glue를 동시에 사용하여 선택적 동맥 색전술을 시행하였다. 색전술 후에는 다시 혈관 조영술 을 시행하여, 재출혈 여부 및 색전술이 성공적으로 시행되었 는지, 합병증은 없는지 다시 한 번 확인하였다.

\section{결 과}

2009년 1월 1일부터 2013년 12월 30일까지 5년간 본원에 서 비출혈로 내원한 2417 명의 환자 중에서 선택적 동맥 색전 술로 치료받은 12 명의 환자 $(0.49 \%)$ 중 외상이 원인인 2 명을 제외한 원인미상의 난치성 자발적 비출혈 환자 10 명의 환자 (0.41\%)를 대상으로 하였다. 10명의 환자 중 남자 6명, 여자 4 명이었으며, 평균 연령은 46.6 12.6 세(range, 32 75세)였다. 10 명의 환자 중 5 명 $(50 \%)$ 의 환자가 고혈압의 기왕력이 있었
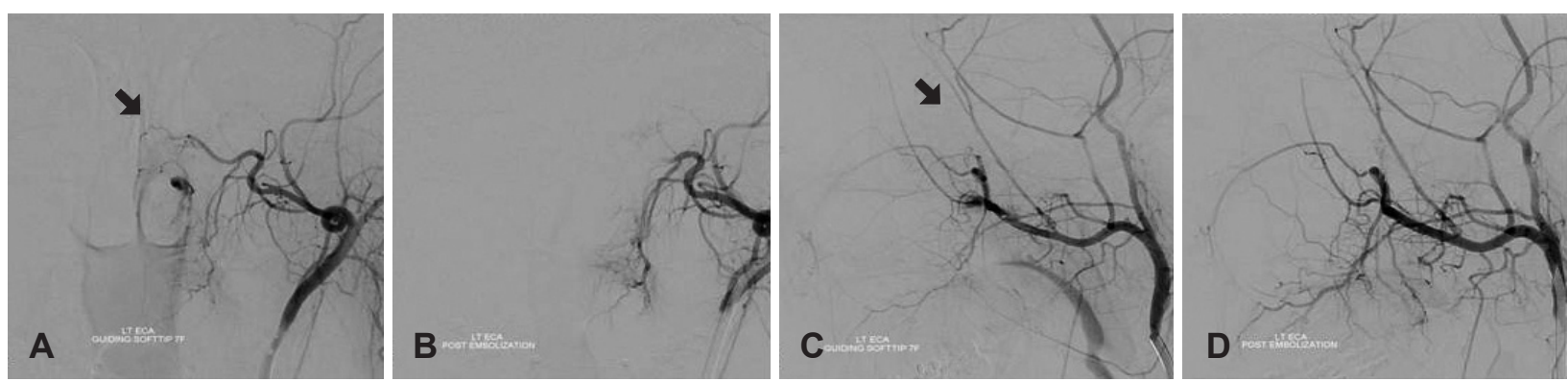

Fig. 1. The case of arterial embolization in patient with retractable epistaxis. Pre-embolization angiogram shows active bleeding from the sphenopalatine artery (arrow) to the left side ( $A$ and $C)$. Post-embolization angiogram shows no bleeding from the sphenopalatine artery (B and D). Pre-embolization angiogram (anteroposterior view) (A). Post-embolization angiogram (lateral view) (B). Pre-embolization angiogram (lateral view) (C). Post-embolization angiogram (lateral view) (D).

Table 1. Demography of recurrent epistaxis patients

\begin{tabular}{|c|c|c|c|c|c|c|c|c|}
\hline No. & Age & Sex & $\begin{array}{l}\text { Bleeding } \\
\text { site }\end{array}$ & $\begin{array}{c}\text { Septal } \\
\text { deviation }\end{array}$ & Risk factors & $\begin{array}{c}\mathrm{Hb} \\
(\mathrm{g} / \mathrm{dL})\end{array}$ & Transfusion & $\begin{array}{c}\text { Management } \\
\text { (before embolization) }\end{array}$ \\
\hline 1 & 46 & $\mathrm{~F}$ & Both & $\mathrm{Lt}$ & HTN & 12.5 & None & Packing, cauterization \\
\hline 2 & 59 & $M$ & $\mathrm{R} \dagger$ & $\mathrm{R} \dagger$ & HTN, LC & 7.5 & Yes & Packing, cauterization \\
\hline 3 & 36 & $\mathrm{~F}$ & $\mathrm{~L} \dagger$ & None & None & 7.5 & Yes & Packing, cauterization \\
\hline 4 & 75 & $\mathrm{~F}$ & $\mathrm{R} \dagger$ & $\mathrm{L} t$ & HTN, ASA & 11.0 & None & Packing \\
\hline 5 & 42 & $M$ & $\mathrm{R} t$ & Rt & $\mathrm{HTN}$ & 14.5 & None & Packing \\
\hline 6 & 47 & M & $\mathrm{L} \dagger$ & $\mathrm{L} \dagger$ & None & 11.3 & None & Packing \\
\hline 7 & 50 & $M$ & $\mathrm{~L} \dagger$ & $\mathrm{L} \dagger$ & None & 12.1 & None & Packing \\
\hline 8 & 37 & $M$ & $\mathrm{~L} \dagger$ & None & None & 10.4 & None & Packing \\
\hline 9 & 32 & $\mathrm{~F}$ & $\mathrm{R} \dagger$ & $\mathrm{L} \dagger$ & None & 6.8 & Yes & Packing \\
\hline 10 & 42 & $M$ & $\mathrm{~L} \dagger$ & $\mathrm{R} \dagger$ & HTN & 10.1 & None & Packing \\
\hline
\end{tabular}

No: number, Hb: hemoglobin, F: female, M: male, Lt: left, Rt: right, HTN: hypertension, LC: liver cirrhosis, ASA: aspirin medication 
Selective Arterial Embolization in Intractable Recurrent Epistaxis I Choi MS, et al.

Table 2. Angiographic embolization findings and clinical course after embolization

\begin{tabular}{cclcc}
\hline No. & $\begin{array}{c}\text { Bleeding focus at } \\
\text { angiography }\end{array}$ & \multicolumn{1}{c}{ Embolization } & $\begin{array}{c}\text { Complication } \\
\text { Follow-up } \\
\text { (weeks) }\end{array}$ \\
\hline 1 & Both SPA & Both SPA with PVA particles & None & NER (2) \\
2 & Unknown & Ipsilateral distal IMA(3rd portion) with PVA particles & None & NER (12) \\
3 & SPA & Ipsilateral SPA with 25\% glue & None & NER (4) \\
4 & SPA & Ipsilateral SPA with PVA particles & Mild fever & NER (5) \\
5 & SPA & Ipsilateral SPA with PVA particles & None & NER (2) \\
6 & SPA & Ipsilateral SPA with PVA particles & Voiding difficulty, NER (2) & groin pain \\
7 & Unknown & Ipsilateral distal IMA(3rd portion) with PVA particles & None & NER (3) \\
8 & Unknown & Ipsilateral distal IMA(3rd portion) with PVA particles & None & NER (8) \\
9 & SPA & Ipsilateral distal IMA(3rd portion) with PVA particles and 20\% glve & None & NER (12) \\
10 & Unknown & Ipsilateral distal IMA(3rd portion) with PVA particles & None & Rebleeding (4)
\end{tabular}

SPA: sphenopalatine artery, IMA: internal maxillary artery, PVA: polyvinyl alcohol, NER: no evidence of recurrent epistaxis

으며, 출혈성 경향을 보일 수 있는 위험인자로 아스피린을 복 용 중이던 환자가 1명(10\%), 간경화의 기왕력이 있는 환자가 1명 (10\%)이었다. 색전술 시행 전 출혈 정도를 평가하기 위한 평 균 혈중 혈색소 수치(hemoglobin)는 $10.37 \pm 2.49 \mathrm{~g} / \mathrm{dL}$ (range, 6.8 14.5 g/dL)였으며, 3명(30\%)의 환자에서 출혈량이 많아 수혈을 시행하였다(Table 1).

10명의 환자 중 6명(60\%)에서 혈관 조영술을 시행 중에 출 혈부위를 발견할 수 있었으며 모두 IMA 말단분지인 접형 구개 동맥에서의 출혈이었다. 정확한 출혈부위가 확인되지 않은 경우는 4명(40\%)이었다. 선택적 동맥 색전술 후 심각한 합병 증은 없었으며, 경미한 합병증이 있었던 경우는 전체 12 명 의 환자 중 2명(16.7\%)으로 1예는 경도의 발열, 1 예는 도관삽입 부위의 통증 및 배뇨장애 등의 경미한 증상을 호소하였고 곧 바로 회복되었다. 그 이외의 합병증은 없었다. 혈관 조영 술 결과 명확한 출혈부위가 관찰되지 않아 IMA의 말단분지 에 색전술을 시행하였던 4 명의 환자 중 1 명의 환자에서 시술 후 1 일째 다시 비출혈이 재발하였으며, 출혈양은 색전술 시행 전보다 적고 환자가 재 동맥 색전술을 원하지 않아 비강 패킹으 로 지혈되었으며 그 후 재출혈은 없었다. 그 이외의 9 명(90\%)의 환자에서는 색전술 시행 후 비출혈이 지혈되었으며 그 이후 재 발은 관찰되지 않았다(Table 2).

\section{고 찰}

비출혈은 이비인후과 의료진에게 흔한 응급 질환 중 하나 로, 대부분 전비공 패킹이나 전기 소작술 등의 보존적 방법 으로 치유되나, 이러한 보존적 방법으로도 지혈되지 않는 난 치성 재발성 비출혈의 경우 고혈압, 만성 신부전, 간질환, 혈 액학적 이상으로 인한 혈액 응고 장애 등이 그 위험 요인으로 고려되며, 고혈압의 경우 모든 비출혈 환자의 약 $5 \sim 23 \%$ 정도 ${ }^{3,4}$
에서 동반되는 것에 비해 본 연구에서는 대상 환자의 수가 10 명으로 적어 정확한 비교는 어려우나 $50 \%$ 정도로 더 많았다. 이는 본 연구에서 환자들이 고혈압이 있는 경우 일반적인 일 차적 비출혈의 처치에도 치료의 효과가 적어 결국 선택적 동 맥 색전술을 시행하게 되는 중요 요인 중 하나로 생각된다.

지혈되지 않는 비출혈의 경우 대개 비강 후방 출혈이 많아 비강 패킹으로 Woodruff's plexus 부위를 효과적으로 압박 하기 어려워 재출혈이 일어나는 경우가 많다. 그러므로, 이러 한 난치성 재발성 비출혈의 치료는 출혈 혈관을 직접 선택적 으로 색전하는 선택적 동맥 색전술이나 결찰하는 방법이 유용 할 수 있다. 이 중 선택적 동맥 색전술은 IMA 결찰술보다 출혈 혈관을 좀더 출혈 위치에 근접하여 색전술을 시행하여 측부 순환에 의한 지속적 재발적인 출혈을 줄일 수 있으므로 보다 선택적으로 근위부의 다른 혈관들을 보존할 수 있어 더 이상 적으로 생각되고 있다. ${ }^{5}$

선택적 동맥 색전술은 최근에 발달된 중재적 방사선 기법

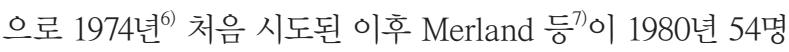
의 난치성 비출혈 환자를 대상으로 $97 \%$ 의 성공률을 보고하 면서 그 후 점차 효과적인 난치성 비출혈의 치료로 이용되고 있다. 선택적 동맥 색전술은 전신마취가 필요 없으며 색전 후 지혈의 결과를 바로 확인할 수 있고 반복적인 시술이 가능한 장점이 있다. 또한 시술 전 시행하는 외경 동맥과 내경 동맥의 혈관 조영술을 통해 조영제의 혈관 외 유출을 통한 정확한 출 혈 부위의 진단 및 다른 외상성 가상 동맥류, 혈관 기형 등을 진단할 수 있으며, 내경 동맥과 외경 동맥 사이의 비정상적인 문합 여부를 관찰하여 색전술 후 발생할 수 있는 뇌혈관 이상 및 시력 손상 등의 합병증을 피할 수도 있다.

동맥 색전술의 금기증으로는 내, 외경동맥 사이의 비정상 적인 문합이 있는 경우, 출혈 부위가 사골동맥인 경우, 조영 제 과민증, 심각한 동맥경화증 등이다.,8) 
선택적 동맥 색전술의 치료 성공률은 보고마다 차이가 있 으나 71 97\%까지 보고되고 있으며, ${ }^{9)}$ 본 연구의 경우 후향적 조사를 통한 연구이며 대상 환자의 수가 적고, 환자 대상의 선정상의 편향이 있을 수 있어 제한점이 있으나 다른 보고자 들의 성공률과 비슷한 $91.7 \%$ 의 성공률을 보였다. 색전술을 시행하는 혈관들에 대한 여러 문헌 보고를 살펴보면, 양측 $\mathrm{IMA}$ 와 함께 동측 안면 동맥을 같이 색전술을 시행하는 문 헌이 27 48\%, 양측 IMA에 색전술을 시행하는 경우가 15 $35 \%$, 일측 IMA만 시행하는 경우가 13 70\% 정도로 보고되 었다. ${ }^{10)}$ Gottumukkala 등은 양측 IMA 및 경우에 따라 안 면 동맥을 포함한 색전술을 동시에 시행하여 시술 후 재출혈 의 빈도를 낮출 수 있음을 보고하였으나 이러한 여러 혈관들 에 비선택적으로 색전술을 시행하는 것은 합병증의 발병을 높일 수 있으므로 주의해야 한다고 언급하였다. 또한 대부분 의 연구에서 색전술의 재출혈은 시술 후 1 2일에 발생하는 경우가 많았으므로, 시술 후 1 2일에는 안정가료 및 재출혈의 관찰이 필요할 것으로 사료된다.

색전술 후 발생할 수 있는 심각한 합병증은 뇌경색, ${ }^{11-17)}$ 시술 부위의 점막 및 피부괴사, $, 12,18-20)$ 영구적인 시력 손상이나 안구마 비 등 ${ }^{12,16)}$ 이 발생할 수 있는 것으로 보고되고 있다.

심각한 합병증이 발생률은 문헌마다 차이가 있으나, 뇌경 색(1 6\%), ${ }^{11-17)}$ 점막 및 피부괴사(1 7\%), ${ }^{9,12,18-20)}$ 영구적인 시력 손상이나 안구마비(2 4\%) ${ }^{12,16)}$ 등이다. 이러한 합병증은 색전술 에 사용된 입자의 크기 중 더 작은 입자(45 150 $\mu \mathrm{m})$ 가 안면부 의 주위 조직의 괴사가 발생할 위험성이 높은 것으로 보고되 고 있다. ${ }^{10)}$ 경미한 합병증의 경우 안면부나 턱의 통증이 가장 흔하게 보고되었고, 안면부의 감각이상, 두통, 경미한 발열, 도관삽입 부의 혈관종 등이 발생할 수 있으며, 이는 일시적 증 상으로 곧 회복되는 것으로 보고되었다. 본 연구 조사에서는 경미한 발열 및 도관 삽입 부위의 통증과 일시적 배뇨장애 등의 경미한 합병증이 관찰되었으나 이는 곧 호전되었으며 그 이외의 합병증은 관찰되지 않았다. 이러한 합병증의 발생 은 색전술에 사용된 입자가 더 작을수록, 여러 혈관에 색전 술을 시행한 경우 더 위험성이 증가하는 경향이 있어, ${ }^{9,10)}$ 적 절한 크기의 색전 물질을 이용한 출혈부위에 근접하여 선택 적으로 색전술을 시행하는 것이 합병증을 예방하는 데 필요 할 것으로 사료된다.

\section{REFERENCES}

1) Small M, Murray JA, Maran AG. A study of patients with epistaxis requiring admission to hospital. Health Bull (Edinb) 1982;40(1):20-9.

2) Park SH, Shin SY, Cho JS, Jin YW, Hong NP. Arterial embolization in rhinological field: an analysis of 19 cases. Korean J OtolaryngolHead Neck Surg 2001;44(1):64-70.

3) Lim SK, Joo EJ, Kang KS, Wee SJ, Kang JH, Park JM. Clinical analysis of refractory epistaxis. Korean J Otolaryngol-Head Neck Surg 2005; 48(9):1111-4.

4) Kim SW, Lee MH, Maeng CH, Yun DG, Kim CD. Clinical analysis of epistaxis : result of the recent 10 years. Korean J Otolaryngol-Head Neck Surg 2000;43(11):1216-21.

5) Siniluoto TM, Leinonen AS, Karttunen AI, Karjalainen HK, Jokinen KE. Embolization for the treatment of posterior epistaxis. An analysis of 31 cases. Arch Otolaryngol Head Neck Surg 1993;119 (8):837-41.

6) Sokoloff J, Wickbom I, McDonald D, Brahme F, Goergen TC, Goldberger LE. Therapeutic percutaneous embolization in intractable epistaxis. Radiology 1974;111:285-7.

7) Merland JJ, Melki JP, Chiras J, Riche MC, Hadjean E. Place of embolization in the treatment of severe epistaxis. Laryngoscope 1980; 90(10 Pt 1):1694-704.

8) Nicolaides A, Gray R, Pfleiderer A. A new approach to the management of acute epistaxis. Clin Otolaryngol Allied Sci 1991;16:59-61.

9) Gottumukkala R, Kadkhodayan Y, Moran CJ, Cross de WT 3rd, Derdeyn CP. Impact of vessel choice on outcomes of polyvinyl alcohol embolization for intractable idiopathic epistaxis. J Vasc Interv Radiol 2013;24(2):234-9.

10) Krajina A, Chrobok V. Radiological diagnosis and management of epistaxis. Cardiovasc Intervent Radiol 2014;37:26-36.

11) Tseng EY, Narducci CA, Willing SJ, Sillers MJ. Angiographic embolization for epistaxis: a review of 114 cases. Laryngoscope 1998; 108(4 Pt 1):615-9.

12) Elden L, Montanera W, Terbrugge K, Willinsky R, Lasjaunias P, Charles D. Angiographic embolization for the treatment of epistaxis: a review of 108 cases. Otolaryngol Head Neck Surg 1994;111(1):44-50.

13) Remonda L, Schroth G, Caversaccio M, Lädrach K, Lövblad KO, Zbären P, et al. Endovascular treatment of acute and subacute hemorrhage in the head and neck. Arch Otolaryngol Head Neck Surg 2000;126(10):1255-62.

14) Vitek J. Idiopathic intractable epistaxis: endovascular therapy. Radiology 1991;181(1):113-6.

15) Elahi MM, Parnes LS, Fox AJ, Pelz DM, Lee DH. Therapeutic embolization in the treatment of intractable epistaxis. Arch Otolaryngol Head Neck Surg 1995;121(1):65-9.

16) Moreau S, De Rugy MG, Babin E, Courtheoux P, Valdazo A. Supraselective embolization in intractable epistaxis: review of 45 cases. Laryngoscope 1998;108(6):887-8.

17) Christensen NP, Smith DS, Barnwell SL, Wax MK. Arterial embolization in the management of posterior epistaxis. Otolaryngol Head Neck Surg 2005;133(5):748-53.

18) Andersen PJ, Kjeldsen AD, Nepper-Rasmussen J. Selective embolization in the treatment of intractable epistaxis. Acta Otolaryngol 2005;125(3):293-7.

19) Sadri M, Midwinter K, Ahmed A, Parker A. Assessment of safety and efficacy of arterial embolisation in the management of intractable epistaxis. Eur Arch Otorhinolaryngol 2006;263(6):560-6.

20) Strach K, Schröck A, Wilhelm K, Greschus S, Tschampa H, Möhlenbruch M, et al. Endovascular treatment of epistaxis: indications, management, and outcome. Cardiovasc Intervent Radiol 2011;34(6): $1190-8$. 